\title{
DIMENSÃO JURÍDICA DA LOUCURA E MODELOS DE ATENÇÃo À SAÚDE MENTAL EM DOM QUIXOTE
}

\author{
Luis Carlos Cancellier de OLIVO ${ }^{1}$ \\ LEONARDO HENRIQUE MARQUES LEHMANN ${ }^{2}$
}

\begin{abstract}
RESUMO: Este breve estudo tem como objetivo analisar as questões da dimensão jurídica da loucura e dos modelos de atenção à saúde mental vigentes no passado e na atualidade, com destaque para a repercussão desses modelos no ordenamento jurídico brasileiro, realizando-se um paralelo com a forma utilizada por Cervantes para retratar as medidas imaginadas por este autor como caminho para lidar com a loucura de Dom Quixote. Realiza-se também um contraponto entre o Dom Quixote de Cervantes e o de Avellaneda, procurando-se demonstrar a nítida diferença de enfoque entre o autor original e o apócrifo no tocante à política de atenção à saúde mental, transpondo essa diferença para o ordenamento jurídico brasileiro, em suas contradições e em suas dificuldades na implantação de um novo paradigma baseado na cidadania e na liberdade do sujeito.
\end{abstract}

Palavras-chave: direito e literatura; direito sanitário; saúde mental; loucura; Dom Quixote.

\section{INTRODUÇÃO}

O presente estudo tem por escopo relacionar a obra Dom Quixote, de Miguel de Cervantes, com a dimensão jurídica da loucura e com as políticas de atenção à saúde mental vigentes no passado e na atualidade.

Para tanto, iniciar-se-á o estudo com a análise dos pontos de partida e de chegada do Cavaleiro da Triste Figura em cada uma de suas andanças, a fim de se estabelecer quais as medidas imaginadas por Cervantes como caminho para lidar com a loucura de Dom Quixote, contrapondo-as com a

1 Doutor em Direito (UFSC). Diretor do Centro de Ciências Jurídicas da Universidade Federal de Santa Catarina. Coordenador do Literato - Grupo de Pesquisa em Direito e Literatura (CNPq). E-mail: cancellier@uol.com.br

2 Doutorando em Direito (Navarra/Espanha). Mestre em Direito (UFSC) Professor da Escola do Ministério Público de Santa Catarina. E-mail: llehmann@mpsc.mp.br 
opção de Avellaneda, autor de obra apócrifa contemporânea à obra-prima cervantina.

Na sequência, com os objetivos de situar a mudança de paradigma que estava a se operar no contexto seiscentista e de demonstrar as conexões entre a obra cervantina, o Direito e a loucura, esboçar-se-á um breve histórico desta, dos gregos até o advento da psiquiatria, passando-se a discorrer sobre a política de saúde mental no Brasil, a eclosão da reforma psiquiátrica, em curso a partir de meados do século passado, e a busca de novos modelos no país, culminando com o ordenamento jurídico nacional ora vigente.

Por fim, com o necessário aporte histórico procedido, retomar-se-á o contraponto entre Cervantes e Avellaneda, situando-o não apenas no contexto de alteração paradigmática operada no século XVII, mas também traçando um paralelo com a transição hoje vivenciada, marcada por contradições e dificuldades na implantação de um novo modelo de atenção à saúde mental, fulcrado na cidadania e na liberdade do sujeito.

\section{OS PONTOS DE PARTIDA}

\section{E DE CHEGADA DE DOM QUIXOTE}

As andanças do Cavaleiro da Triste Figura têm, nos dois volumes idealizados por Cervantes, o primeiro publicado em 1605 e o segundo em 1615, um ano antes da morte do autor, os mesmos pontos de partida e de chegada. Com efeito, tanto O Engenhoso Fidalgo D. Quixote de La Mancha, de 1605, quanto O Engenhoso Cavaleiro D. Quixote de La Mancha, de 1615, partem da casa do fidalgo manchego, na qual convive Dom Quixote, que beirava a casa dos cinquenta, com sua ama "que passava dos quarenta" e sua sobrinha "que não chegava aos vinte", e a ela tornam, no primeiro livro por duas vezes, dadas as duas saídas que nele se relatam, e no segundo livro por uma vez. Em todas as saídas relatadas, as quais empreende "para desfazer agravos e endireitar tortos”, Dom Quixote deixa sua ama e sua sobrinha, bem como os amigos de sua aldeia, o padre e o barbeiro, e depois o bacharel Sansón Carrasco, alvoroçados com seu desaparecimento e preocupados com sua condição. 
Assim é descrito o cenário por ocasião do primeiro retorno ao lar do manchego, quando é trazido, alquebrado, por um lavrador conhecido da aldeia:

Chegada pois a hora que lhe pareceu, entrou na vila e na casa de D. Quixote, a qual achou em grande alvoroço, estando nela o padre e o barbeiro do lugar, que eram grandes amigos de D. Quixote, aos quais a ama ia dizendo a altas vozes:

- Que me diz vossa mercê, senhor licenciado Pero Pérez que assim se chamava o padre -, da desgraça do meu senhor? Três dias faz que não há sinal dele, nem do rocim, nem da adarga, nem da lança, nem das armas. Ai de mim! Pois eu aqui entendo, e à fé que isto é verdade como eu nasci para morrer, que esses malditos livros de cavalarias que ele tem e tão de ordinário costuma ler lhe transformaram o juízo; e agora me lembro de o ter ouvido dizer muitas vezes, falando sozinho, que queria armar-se cavaleiro andante e ir buscar as aventuras por esses mundos. Encomendados sejam a Satanás e a Barrabás esses livros, que assim botaram a perder o mais delicado entendimento que havia em toda La Mancha.

A sobrinha dizia o mesmo, e ainda dizia mais:

- Saiba, senhor mestre Nicolás - que esse era o nome do barbeiro -, que muitas vezes aconteceu ao meu senhor tio estar lendo nesses desalmados livros de desventuras dois dias com suas noites, ao cabo dos quais atirava o livro longe, e arrancava a espada, e andava às cutiladas com as paredes; e quando estava muito cansado dizia que tinha matado quatro gigantes como quatro torres, e o suor que suava do cansaço dizia ser o sangue dos ferimentos sofridos na batalha, e bebia em seguida uma grande jarra de água fria, ficava então bom e sossegado, dizendo ser aquela água uma preciosíssima bebida, presente do sábio Esquifo, um grande encantador e amigo seu. Mas eu tenho a culpa de tudo, por não ter avisado vossas mercês dos disparates do meu senhor tio, para que remediassem o dano antes que chegasse ao que chegou, e queimassem todos esses excomungados, que muitos deles bem merecem ser abrasados como coisa de hereges.

- O mesmo digo eu - disse o padre -, e à fé que não há passar o dia de amanhã sem que deles se faça ato público e sejam condenados ao fogo, porque não deem azo a quem os ler de fazer o que o meu bom amigo deve de ter feito.

Tudo isso iam ouvindo o lavrador e D. Quixote, com o que acabou de entender o lavrador o mal de seu vizinho e assim pegou a dar vozes:

- Abram vossas mercês para o senhor Valdovinos e o senhor marquês de Mântua, que vem malferido, e para o senhor mouro Abindarráez, que traz cativo o valoroso Rodrigo de Narváez, alcaide de Antequera. 
A essas vozes saíram todos, e como reconhecessem uns seu amigo, outras seu amo e tio, que ainda não apeara do jumento, porque não podia, correram a abraçá-lo. Ele disse:

- Eia, eramá! - disse a ama nesse ponto. - Eu bem que palpitava de que pé coxeava o meu senhor! Suba vossa mercê embora, pois sem que venha essa tal Purganda, nós aqui saberemos curá-lo. Malditos, digo, sejam outra vez e outras cem esses livros de cavalarias, que assim deixaram vossa mercê!

Levaram-no logo à cama e, procurando-lhe os ferimentos, não acharam nenhum; e ele disse que era tudo moedura, por ter levado um grande tombo com Rocinante, seu cavalo, ao se bater com dez gigantes, os mais desaforados e atrevidos de quantos há em grande parte da terra (Cervantes, 2010a, p. 104-107).

O mesmo cuidado da família e dos amigos se constata por ocasião da segunda volta do Cavaleiro da Triste Figura à sua aldeia, após mirabolante plano engendrado pelo padre Pérez e pelo barbeiro Nicolás, com o objetivo de trazê-lo de volta a casa para ser tratado:

[...] ao cabo de seis dias chegaram à aldeia de D. Quixote, na qual entraram na metade do dia, que calhou de ser domingo, e toda a gente estava na praça, por onde atravessou o carro de D. Quixote. Acudiram todos a ver o que o carro trazia e, quando conheceram o seu compatrício, ficaram maravilhados, e um rapaz foi correndo dar as novas a sua ama e sua sobrinha de que seu tio e seu senhor vinha magro e amarelo deitado num monte de feno e sobre um carro de bois. Coisa de pena foi ouvir os gritos que as duas senhoras soltaram, as bofetadas que se deram, as maldições que de novo lançaram contra os malditos livros de cavalarias, todo o qual se renovou quando viram entrar D. Quixote por suas portas.

[...] a ama e a sobrinha de D. Quixote o recebiam, e o despiam, e o deitavam no seu antigo leito. Ele as fitava com olhos transtornados, sem atinar onde estava. O padre encareceu à sobrinha que tivesse grande cuidado em bem tratar o seu tio e que estivessem alerta de que não escapasse outra vez, contando o que fora mister para trazê-lo para casa. Aí as duas soltaram novos gritos; aí se renovaram as maldições dos livros de cavalarias, aí pediram ao céu que castigasse no fundo do abismo os autores de tantas mentiras e disparates. Finalmente, ficaram as duas confusas e temerosas de se verem sem o seu amo e tio no momento que ele tivesse alguma melhoria, e de feito sucedeu como elas imaginaram (Cervantes, 2010a, p. 687-689). 
Já no segundo volume de D. Quixote, quando é narrada sua derradeira saída, novamente percebe-se todo o cuidado e a preocupação de sua família antes da nova aventura e, posteriormente, por ocasião de sua volta.

Colhem-se os seguintes trechos relativos aos cuidados dedicados ao Cavaleiro da Triste Figura antes da terceira saída:

Conta Cide Hamete Benegeli, na segunda parte desta história e terceira saída de D. Quixote, que o padre e o barbeiro passaram quase um mês sem o ver, para não renovar nem lhe trazer à memória as coisas passadas. Mas nem por isso deixaram de visitar sua sobrinha e sua ama, recomendando-lhes que tratassem de o regalar, dando-lhe de comer coisas confortativas e apropriadas para o coração e o cérebro, donde (segundo bom discurso) provinha toda a sua má ventura. As quais disseram que assim faziam e fariam com a melhor vontade e cuidado possível, pois viam que seu senhor ia dando mostras de estar cada vez mais em seu inteiro juízo; do qual receberam os dois grande contentamento, por lhes parecer que haviam acertado em trazê-lo encantado no carro de bois (como se contou na primeira parte desta tão grande quanto pontual história, no seu último trecho) [...] (Cervantes, 2010b, p. 53).

E, novamente, os mesmos cuidados são registrados por ocasião de sua terceira e derradeira volta ao lar: "E as boas filhas (que sem dúvida o eram, tanto a ama quanto a sobrinha) o levaram para a cama, onde lhe deram de comer e o regalaram o melhor possível" (Cervantes, 2010b, p. 744).

Da mesma forma, quando o manchego cai doente, desenganado pelo médico, comoventes são as reações daqueles que o cercam ao leito:

Chamaram seus amigos o médico, tomou-lhe o pulso, que não o contentou muito, dizendo que, pelo sim ou pelo não, se cuidasse da saúde da sua alma, porque a do corpo corria perigo. Ouviu-o D. Quixote com ânimo sossegado, mas não o ouviram assim sua ama, sua sobrinha e seu escudeiro, os quais começaram a chorar ternamente, como se já o tivessem morto ante os olhos [...].

Acabou-se a confissão e saiu o padre dizendo:

- Verdadeiramente morre e verdadeiramente está são Alonso Quijano o Bom; bem podemos entrar para que faça seu testamento.

Essas novas deram um terrível empurrão nos olhos prenhes da ama, da sobrinha e de Sancho Pança, seu bom escudeiro, de tal maneira que lhes fez rebentar as lágrimas dos olhos e mil profundos suspiros do peito; porque verdadeiramente, como alguma vez já foi dito, enquanto D. Quixote foi Alonso Quijano o Bom, sem mais, e quando foi D. Quixote de La Mancha, sempre foi de aprazível condição e de agradável trato, e por isso era 
bem amado não só da gente de sua casa, mas de todos quantos o conheciam [...].

Por fim chegou o último de D. Quixote, depois de recebidos todos os sacramentos e depois de ter abominado dos livros de cavalarias com muitas e eficazes razões. Achou-se o escrivão presente e disse que nunca tinha lido em nenhum livro de cavalarias que algum cavaleiro andante morresse em seu leito tão sossegadamente e tão cristão como D. Quixote, o qual, entre compaixões e lágrimas dos que ali se achavam, entregou seu espírito (quero dizer que morreu) (Cervantes, 2010b, p. 746-751).

A par de toda a convivência familiar e o cuidado relatados, é de se ver que em nenhum trecho da obra cogitam seus amigos recolher D. Quixote a alguma das então chamadas casas de loucos, que começavam a se popularizar na Europa. Ao contrário, todos seus esforços, mesmo quando vão em sua busca, são no sentido de, utilizando-se do cenário da própria loucura do Cavaleiro da Triste Figura, buscar meios de fazê-lo retornar ao lar, onde, acreditam, sob os cuidados de suas ama e sobrinha, pode vir a restabelecer o juízo.

Solução diversa foi encontrada no D. Quixote apócrifo de Avellaneda, publicado em 1614, um ano antes da publicação do segundo volume de Cervantes.

Referida obra, pretensa continuação das aventuras do cavaleiro manchego descritas no primeiro volume, e com prólogo recheado de críticas a Cervantes, foi assinada por autor com o pseudônimo de Alonso Fernández de Avellaneda, e, hoje, passados quatro séculos da façanha, ainda se encontra em discussão a identidade do responsável pelo escrito.

Sobre a identidade de Avellaneda, escreve Vieira: "Certamente Cervantes sabia muito bem quem era Avellaneda, mas não mencionará seu nome - seria um modo de imortalizá-lo - e utilizará recursos retóricos para dizer não dizendo, mostrando-se insensível aos agravos do autor apócrifo" (2010, p. 21).

Apesar de não mencionar diretamente a identidade de Avellaneda, Cervantes, no decorrer do segundo volume de D. Quixote, procede a várias referências indiretas ao autor apócrifo, não somente em relação a sua identidade, mas também em relação a passagens e personagens mencionados na obra daquele, procedendo diálogos e mencionando 
referências da obra apócrifa, que o manchego chega a ter em mãos. Comenta Vieira:

O curioso é que não apenas o cavaleiro toma conhecimento de que anda impressa uma falsa versão de suas andanças, escrita por um tal Avellaneda, como também folheia a obra e faz comentários sobre o estilo desse autor que, segundo suas impressões, parece ser aragonês (cap. LIX). Como não bastasse, estando em Barcelona, decide entrar em uma tipografia e ali, entre outros títulos que estão sendo impressos, se defronta com a segunda parte apócrifa (cap. LXII). Mais adiante, já retornando a sua aldeia, encontra-se com uma personagem da obra apócrifa - o cavaleiro granadino D. Álvaro Tarfe - que finalmente reconhece ser ele o verdadeiro D. Quixote (cap. LXXII), e não o protagonista do escritor aragonês (2010, p. 30).

O fato que releva anotar, para o cerne desse artigo, é que ao final da obra apócrifa, D. Quixote é internado em um hospício e isolado da sociedade. Sobre tal solução, escreve Cruz:

\begin{abstract}
Apesar de o louco ser considerado uma figura frequente na sociedade espanhola, não quer dizer que naquela época não havia formas de repreensão dos loucos e de que não havia manicômios, tanto é que o Dom Quixote apócrifo, protagonista de Alonso Fernández de Avellaneda, vive a experiência de ser encarcerado em um hospício, mais especificamente na Casa del Nuncio, que era a casa de loucos de Toledo, o qual havia sido construído no início do séc. XVI, sendo considerado um dos mais importantes hospitais de dementes dos séculos XVI e XVII (2009, p. 133).
\end{abstract}

O momento histórico em que se situa a publicação de D. Quixote é ilustrativo da mudança de paradigma vivenciada no trato das questões relacionadas à loucura, sendo necessário resgatar um breve histórico desta e de suas repercussões, a fim de demonstrar as conexões entre loucura, a obra cervantina e o Direito, histórico que será objeto do próximo item.

\title{
BREVE HISTÓRICO DA LOUCURA
}

O modo de ver a loucura tem se alterado no decorrer da história, refletindo-se na forma como cada ordenamento tem reagido às suas repercussões na sociedade.

Assim é que na Grécia antiga, a loucura era vista como uma forma de manifestação dos deuses. As coisas ditas pelos loucos eram consideradas um saber importante e necessário, capaz mesmo de interferir no destino 
dos homens. Nesse contexto, não havia repressão àqueles que apresentassem algum distúrbio de natureza mental, tendo a loucura experimentado, no período, livre forma de expressão. Menciona Vasconcellos:

\begin{abstract}
Os "mestres da verdade" teriam três designações ou seriam de três espécies: aqueles que previam todos os futuros, que possuíam olhos voltados para a frente, eram chamados de profetas ou adivinhos; os que lembravam de todos os passados, que possuíam olhos voltados para trás, eram chamados de poetas ou aedos; e os que misturavam os elementos da natureza, fazendo deles ungüentos, eram chamados de xamãs ou sacerdotes. Todos eram possuídos pelos deuses. Possessão que, em grego, significa enthousiasmos. O adivinho foi possuído pelo deus Apolo; o aedo pela deusa Mnemosine ou pelas Musas, suas servas; e o sacerdote, pelo deus Dionisos. Tanto o poeta, quanto o profeta e o xamã, passam por um processo de possessão, ou seja, de enlouquecimento para estabelecer contato com as divindades. Foi preciso que houvesse a desrazão para que se estabelecesse a 'razão divina' (2000, p. 15).
\end{abstract}

$\mathrm{Na}$ idade média, a loucura passou a ser considerada como uma expressão das forças da natureza, como algo não humano. Persistia a crença de que a fala incompreensível dos loucos era uma forma de contatar o estranho e de tentar compreender seus mistérios, remanescendo uma espécie de exaltação da loucura, ainda que temperada por um sentimento misto de terror e atração.

A inquisição católica, especialmente a partir do século $\mathrm{XV}$, desempenhou um importante papel na mudança do paradigma do trato da loucura, na medida em que passou a reprimir os diferentes que de alguma forma representassem um risco à hegemonia da Igreja. Nessa esteira, reprimiram-se os judeus, os protestantes, as bruxas e, no contexto destas, os loucos, os quais, passíveis de enquadramento como hereges, ficavam sujeitos ao processo inquisitorial e à execução, muitas vezes por meio da fogueira (Alencar et al., 2003, p. 13-14).

O século XVII traz em seu bojo o império da razão, traduzido pelos primeiros movimentos intelectuais que propunham um novo modelo político que diminuísse o poder absoluto dos reis. A loucura, nesse patamar, passa a ser vista em seu contraponto à razão, como ausência dela. E no império da razão, onde a existência cartesiana é a ela atrelada e 
indissociada ("penso, logo existo") não há outro destino para a loucura que não o banimento. É o que diz Foucault:

A Não-Razão do século XVI constituía uma espécie de ameaça aberta cujos perigos podiam sempre, pelo menos de direito, comprometer as relações da subjetividade e da verdade. $\mathrm{O}$ percurso da dúvida cartesiana parece testemunhar que no século XVII esse perigo está conjurado e que a loucura foi colocada fora do domínio no qual o sujeito detém seus direitos à verdade: domínio este que, para o pensamento clássico, é a própria razão. Doravante, a loucura está exilada. Se o homem pode sempre ser louco, o pensamento, como exercício de soberania de um sujeito que se atribui o dever de perceber o verdadeiro, não pode ser insensato. Traça-se uma linha divisória que logo tornará impossível a experiência, tão familiar à Renascença, de uma Razão irrazoável, de um razoável Desatino. Entre Montaigne e Descartes algo se passou: algo que diz respeito ao advento de uma ratio. Mas é inquietante que a história de uma ratio como a do mundo ocidental se esgote no progresso de um racionalismo; ela se constitui em parte equivalente, ainda que mais secreta, desse movimento com o qual o Desatino mergulhou em nosso solo a fim de nele se perder, sem dúvida, mas também de nele deitar raízes (2010, p. 47-48).

O resultado dessa significativa mudança de paradigma foi a criação, no século XVII, por toda a Europa, de várias casas de internamento, visando a apartar da sociedade não apenas os loucos, mas também todos aqueles considerados incapazes de contribuir no processo de produção, de comércio ou de consumo. Esse movimento, que passou para a história como a "grande internação", veio a atingir idosos e crianças abandonadas, pessoas com deficiência e com doenças venéreas, moradores de rua e também os loucos. Foucault comenta essa reação:

A prática do internamento designa uma nova reação à miséria, um novo patético - de modo mais amplo, um outro relacionamento do homem com aquilo que pode haver de inumano em sua existência. $O$ pobre, o miserável, o homem que não pode responder por sua própria existência, assumiu no decorrer do século XVI uma figura que a Idade Média não teria reconhecido (2010, p. 56).

Foucault (2010, p. 73) afirma não ter sido indiferente o fato de os loucos terem sido envolvidos no que chama de "grande proscrição da ociosidade", asseverando que desde o princípio eles tiveram seu lugar ao lado dos pobres e dos ociosos, sendo, juntamente com estes, submetidos às regras do trabalho obrigatório. 
Com a revolução francesa e os princípios que a inspiraram, de liberdade, igualdade e fraternidade, iniciou-se um processo de reabsorção dos internados pela sociedade, mas os loucos permaneceram encarcerados, por falta de propostas e devido ao estigma de que poderiam se tornar violentos e perigosos a familiares e vizinhos.

Até o final do século XVIII, não se pode dizer que houvesse um real interesse da medicina em saber o que e o porquê das coisas ditas pelo louco. Em 1793, com a nomeação de Pinel para a direção do Bicêtre, hospital francês aonde eram destinados os considerados insanos, é que se passou a difundir uma nova concepção de loucura, afeita à saúde. Pinel concebia a alienação mental como um distúrbio das funções intelectuais do sistema nervoso. Considerava o cérebro como sede da mente, e na mente é que se manifestava a loucura. Dividiu os sintomas em classes: mania, melancolia, demência e idiotismo, e considerava que as principais causas da loucura seriam as físicas, decorrentes do cérebro (traumatismo na cabeça, formação defeituosa do cérebro e hereditariedade) e as morais, consideradas as mais importantes, que seriam decorrentes das paixões intensas e dos excessos de todos os tipos.

A loucura adquire então o status de "doença mental”, que requeria um saber médico e técnicas específicas. A prática da reclusão dos loucos permaneceu, mas agora com o objetivo de estudá-los e de tentar obter a cura, sendo visível, nessa esteira, a prevalência dos conceitos de saúde e de doença numa perspectiva social, ainda que visando à manutenção da ordem pública.

Nesse momento, fica constituída a psiquiatria, tendo como primeira escola o Alienismo como saber médico específico, já que a loucura, como doença, necessitaria de um saber médico particular. O Alienismo se baseava no entendimento da loucura como desrazão, ou seja, alienação mental. Seus principais representantes foram Pinel, na França, e Tuke, na Inglaterra, tendo posteriormente no francês Esquirol um de seus maiores teóricos. $\mathrm{O}$ tratamento era baseado no Asilo, que teria uma função terapêutica, e consistia em confrontar a confusão do louco, sua desrazão, com a ordem do espaço asilar e com a razão do alienista que, para tanto, tinha que ser uma pessoa de moral inatacável.

Foucault é contundente em sua crítica ao modelo asilar: 
O asilo construído pelo escrúpulo de Pinel não serviu para nada e não protegeu o mundo contemporâneo contra a grande maré da loucura. Ou melhor, serviu, serviu muito bem. Se libertou o louco da desumanidade de suas correntes, acorrentou ao louco o homem e sua verdade. Com isso, o homem tem acesso a si mesmo como ser verdadeiro, mas esse ser verdadeiro só lhe é dado na forma da alienação (2010, p. 522).

De fato, a cura almejada por Pinel não foi alcançada e as instituições asilares permaneceram como locais de depósito, abandono e exclusão para pessoas às quais a sociedade não apresentava propostas alternativas de inclusão. Apesar de seu fracasso, a classificação de Pinel continuou a ser utilizada ainda por muito tempo (Alencar et al., 2003, p. 14-16).

\section{POLÍTICA DE SAÚDE MENTAL NO BRASIL}

A criação do primeiro hospício brasileiro, o Pedro II, em 1841, no Rio de Janeiro, pode ser considerada um marco na política de saúde mental no Brasil. O crescimento e o reordenamento do espaço urbano, reproduzindo o que já havia ocorrido nas cidades da Europa, levaram ao recolhimento dos habitantes considerados "desviantes" que perambulavam pelas ruas, desempregados, imigrantes, mendigos, órfãos e também os loucos, aos Asilos de Mendicância e de Órfãos, administrados pela Santa Casa de Misericórdia, vinculada à igreja católica. Os loucos eram colocados no mesmo lugar que os demais "desviantes", sendo submetidos a maus tratos que frequentemente os levavam à morte. Em 1830, médicos, aliados ao provedor da Santa Casa de Misericórdia, José Clemente Pereira, iniciaram um movimento destinado a criar um lugar específico para os loucos, movimento que ficou conhecido pelo lema "aos loucos o hospício" e que resultou na criação do Pedro II, inaugurado em 1852, sem que cessassem, contudo, as críticas, por parte dos médicos, aos maus tratos, à superlotação e à ausência de cura aos considerados "doentes mentais".

Em 1890, o Pedro II passou a chamar-se Hospício Nacional de Alienados, refletindo a escola psiquiátrica então em voga. Como reflexo da recente proclamação da república, o poder gerencial dos religiosos foi substituído pelo dos médicos e a proposta terapêutica permaneceu a do "tratamento moral", baseado no isolamento e na organização do espaço terapêutico, preconizados por Pinel e Esquirol. 
Nas décadas de 1910 e 1920, destacaram-se a proposta terapêutica do trabalho agrícola e de pequenas oficinas, com Juliano Moreira como seu teórico mais importante, e a assistência hétero-familiar (AHF) tendo como modelo a colônia de Geel, na Bélgica, na qual os doentes eram acolhidos nas casas de moradores e apresentavam melhoras em seu estado mental. Ambas as propostas não levaram à almejada "cura" dos pacientes e o considerado mau resultado das iniciativas reforçaram o modelo do sistema fechado, tendo ganhado força a proposta da "hospitalização definitiva" para os doentes crônicos, considerados incuráveis.

Nas décadas de 1940 e 1950, houve o predomínio das terapias biológicas, marcadas por eletroconvulsoterapia, lobotomias, terapia insulínica e novos medicamentos, vendo a década de 1960 o declínio da psiquiatria pública, com o correspondente crescimento da psiquiatria privada (Alencar et al., 2003, p. 16-21).

\section{AS REFORMAS PSIQUIÁTRICAS}

Desde Pinel, pouco se evoluiu em termos de propostas para lidar com os então chamados doentes mentais, principalmente no tocante à sua exclusão do meio social. O final da segunda guerra mundial, contudo, trouxe ao mundo, de forma traumática, a necessidade de mão de obra para reconstrução, aliada a uma nova ordem vigente, incompatível com maus tratos e mesmo o extermínio dos chamados doentes mentais, já que muitos foram executados em razão dessa condição pelos regimes fascistas que seduziram a Europa e que patrocinaram abertamente a eugenia.

O mundo pós-guerra viu, então, nascerem algumas experiências que causaram uma radical mudança no foco da psiquiatria, que deixou de ser a "busca da cura" da doença mental, para passar a ser a promoção da saúde mental por meio da adaptação social. Dentre essas experiências podem ser destacadas a comunidade terapêutica, a psicoterapia institucional, a psiquiatria comunitária ou preventiva, a antipsiquiatria e a psiquiatria democrática italiana.

A comunidade terapêutica surgiu na Inglaterra, com Maxwell Jones, e baseava-se na democracia das relações, procurando enfatizar a participação de todos na organização das atividades, na administração do hospital, no aspecto terapêutico, com ênfase no trabalho. É de se destacar, contudo, que 
essa experiência insistia na ação dentro da instituição, comungando, dessa forma, com a recusa ainda procedida pela sociedade em conviver com os diferentes.

A psiquiatria institucional encontra seu marco na França, com Tosquelles. Insistia na restauração do aspecto terapêutico do hospital psiquiátrico, procurando livrá-lo do estigma de ter se transformado em lugar de violência e repressão. Todavia, a psiquiatria institucional abstraíase da realidade social na qual vivia o sujeito com problemas psíquicos.

A psiquiatria comunitária ou preventiva tem sua origem nos Estados Unidos, nos anos de 1960, durante o governo Kennedy, tendo sido fortemente influenciada pelos trabalhos de Caplan. Buscava uma aproximação com a saúde pública em geral, procurando intervir nas causas do surgimento das doenças, visando à prevenção. Chegou a ser adotada como modelo pela Organização Mundial de Saúde e pela Organização PanAmericana de Saúde, e, embora tenha trazido uma importante contribuição, ao focar o tema da prevenção, hoje se encontra superado o pensamento de que o conceito de prevenção se aplique ao campo da saúde mental da mesma forma como se aplica em outras áreas da saúde.

A antipsiquiatria começa na Inglaterra, na década de 1960, com Laing e Cooper, sustentando que a psiquiatria não estava conseguindo responder aos problemas vivenciados pelo sujeito com problemas psíquicos. Considerava a loucura como um fato social, político e mesmo como uma experiência de libertação. A família já era chave nesse processo, sendo a loucura considerada uma reação a um desequilíbrio familiar. Defendia que o delírio do louco não deve ser contido, mas acompanhado pelo grupo, por meio de recursos como o psicodrama e a regressão, procurando-se, como saída possível, a modificação da realidade social.

Finalmente, a psiquiatria democrática italiana, surgida no final da década de 1960 e tendo Franco Basaglia como seu precursor, procura recuperar a complexidade da loucura, partindo do pressuposto de que esta diz respeito ao homem, à sociedade e à família e que, portanto, não é a psiquiatria, sozinha, que dará conta de resolver os problemas a ela relacionados. Não nega a existência da doença mental, mas propõe uma maneira mais ampla de se lidar com ela. O tratamento deve ocorrer na comunidade, o que faz com que o hospital psiquiátrico perca sua razão de 
ser, já que ele se caracterizaria como local de repressão e sofrimento, e não de cuidado. A psiquiatria democrática italiana causou bastante repercussão no Brasil, inspirando algumas importantes iniciativas e influenciando fortemente a construção de nossa política de atenção à saúde mental, como irá se ver no item seguinte (Alencar et al., 2003, p. 21-27).

\section{A BUSCA DE NOVOS MODELOS EM SAÚDE MENTAL NO BRASIL}

Em nosso país, o modelo tradicional, baseado na exclusão, já vinha mostrando sinais de esgotamento desde o final da década de 1970. Essa época, marcada por um contexto de redemocratização política, viu os trabalhadores de saúde passarem a denunciar as péssimas condições a que eram submetidos os pacientes em manicômios, decorrentes da utilização de celas fortes, espancamentos e falta de higiene.

Em 1978, foi criado o Movimento de Trabalhadores em Saúde Mental, que buscava articular propostas e ações contra o modelo vigente, tendo início as primeiras tentativas de modificação do sistema asilar.

Em 1987, ocorre a I Conferência Nacional de Saúde Mental, na qual se firmou o primeiro consenso mínimo entre os técnicos no sentido da necessidade de modificação do modelo de assistência psiquiátrica.

A II Conferência Nacional de Saúde Mental, em 1992, realizada já sob os pressupostos da Constituição de 1988, contou com a participação de representantes de usuários, de trabalhadores e de prestadores de serviços, tendo discutido a reestruturação da atenção à saúde mental no Brasil, no contexto dos princípios da municipalização e da cidadania das pessoas com transtornos psíquicos.

As propostas e discussões realizadas culminaram com a publicação, em 06 de abril de 2001, da Lei Federal $n^{0}$ 10.216, com visível inspiração na psiquiatria democrática italiana, que dispôs sobre a proteção e os direitos das pessoas portadoras de transtornos mentais, redirecionando o modelo assistencial em saúde mental para firmar a estratégia dos serviços comunitários de saúde mental (Centros de Atenção Psicossocial - CAPS) como dispositivos prioritários para a organização da atenção em saúde mental. 
Destacam-se do referido diploma legal, particularmente, o estabelecimento expresso do direito da pessoa com transtorno mental a ser tratada com humanidade e respeito e no interesse exclusivo de beneficiar sua saúde, visando a alcançar sua recuperação pela inserção na família, no trabalho e na comunidade, e a ser tratada, preferencialmente, em serviços comunitários de saúde mental (art. $2^{\circ}$, II e IX).

Estabelece também a Lei n. 10.216/2001, em seu art. $4^{\circ}$, a internação como exceção no tratamento da pessoa com transtorno mental, sendo indicada somente na hipótese de os recursos extra-hospitalares se mostrarem insuficientes e, ainda assim, visando, como finalidade permanente, à reinserção social do paciente em seu meio. Outrossim, passou a ser expressamente vedada a internação de pacientes com transtornos mentais em instituições com características asilares.

O marco legal hoje vigente no Brasil, pois, focado na cidadania e na liberdade do indivíduo, é claro no sentido de estabelecer a política de inserção da pessoa com transtornos mentais na sociedade, com a participação da família e dos serviços comunitários de saúde mental como prioritários no tratamento, afigurando-se a segregação como absoluta exceção à regra vigente.

\section{O CONTRAPONTO CERVANTES-AVELLANEDA}

Uma vez procedido esse necessário aporte histórico, é relevante perceber que a visão de Cervantes sobre a loucura e a forma de tratá-la é em grande parte compatível com o modelo de assistência psicossocial que preza o envolvimento da família e do meio social, colocando a cidadania do sujeito com transtorno psíquico no centro do tratamento a ser concebido.

Já Avellaneda, na conclusão de sua obra, opta pelo modelo que passaria a vigorar principalmente a partir do século XVIII, baseado no isolamento e na segregação, e que se estenderia até os meados e final do século XX.

Como as duas obras são contemporâneas, verifica-se a clara mudança de paradigma que se operava na ocasião. A opção de Avellaneda é como uma prospecção do brutal isolamento que se estenderia dali a até praticamente o final do século XX, compreendendo quase quatrocentos anos de negação de cidadania ao protagonista da loucura. Cervantes, por 
outro lado, ainda traz uma abordagem que vê o sujeito com transtorno psíquico em sua complexidade, inserido na sociedade com toda sua riqueza e peculiaridade, distante do banimento que lhe seria imposto pelo império da razão inaugurado pela era clássica. Segundo Foucault:

Esse mundo do começo do século XVII é estranhamente
hospitaleiro para com a loucura. Ela ali está presente, no
coração das coisas e dos homens, signo irônico que
embaralha as referências do verdadeiro e do quimérico,
mal guardando a lembrança das grandes ameaças
trágicas - vida mais perturbada que inquietante, agitação
irrisória na sociedade, mobilidade da razão (2010, p. 44).

Este cenário começaria a mudar no decorrer do séc. XVII, sendo bastante significativa a opção de Avellaneda de isolar D. Quixote da sociedade, como sinal dessa mudança de paradigma.

Cervantes, como visto, opta por manter D. Quixote junto à sua família e junto aos seus, e mesmo o "tratamento" proposto é de extremo respeito à pessoa do fidalgo, procurando-se adentrar em seu mundo, em sua verdade, para, por meio de artifícios, procurar trazê-lo de volta à sua vila. São bastante representativos, nesse sentido, os planos engendrados pelo padre e pelo barbeiro, no primeiro livro, e pelo licenciado Sansón Carrasco, no segundo, com vistas a tornar o manchego ao seu lar.

Ademais, Cervantes constrói um personagem profundo, com relevo e personalidade, enquanto Avellaneda pinta um Quixote superficial, equiparado a um boneco, nas palavras de García Salinero:

[...] mientras el don Quijote cervantino adquiere un relieve y una personalidad que hacen innecessaria la presencia del autor, este Quijote de alfeñique es uma intelequia usada constantemente como marioneta de guiñol; como un ventrílocuo que se valiese de muñecos, Avellaneda usa a este don Quijote para espetar por él uma perorata absurda. En suma, don Quijote se hace carne y alma em Cervantes; en la obra apócrifa, es um simbólico altavoz por medio del cual llega al lector el monologo fastidioso que le invita constantemente a no ser necio [...] (1999, p. 13).

Esse respeito à verdade subjetiva do fidalgo é característico da obra cervantina e encontra eco na forma como a loucura era tratada na época. Conforme Foucault:

Antes do século XVIII, a loucura não era sistematicamente internada, e era essencialmente considerada como uma forma de erro ou de ilusão. Ainda no começo da idade clássica, a loucura era vista como 
pertencendo às quimeras do mundo; podia viver no meio delas e seria separada no caso de tomar formas extremas ou perigosas. Nestas condições compreende-se a impossibilidade do espaço artificial do hospital em ser um lugar privilegiado, onde a loucura podia e devia explodir em sua verdade (2011, p. 120).

Na época clássica, como se refere Foucault, a transcendência do delírio assegurava à loucura uma espécie de interioridade que nunca se espalhava pelo exterior, mantendo-a num relacionamento consigo mesma (2010, p. 516).

A partir do século XVIII, observa-se um movimento no sentido inverso. Num primeiro momento, simplesmente, segrega-se o diferente. Após, com Pinel e Tuke, inicia-se um processo de objetivação da verdade no tratamento da loucura. A verdade da loucura deve surgir de forma objetiva, relacionada a parâmetros externos previamente definidos, estabelecendose, assim, a curiosa função do hospital psiquiátrico do século XIX, como lugar de classificação e de diagnóstico, "retângulo botânico onde as espécies de doenças são divididas em compartimentos cuja disposição lembra uma vasta horta" (Foucault, 2011, p. 122). A loucura passa a ter seu equivalente externo, escorraçando o homem para fora de si mesmo e estendendo-o ao nível de uma natureza pura e simples, ao nível das coisas (Foucault, 2010, p. 516).

Avellaneda começa a caminhada nessa direção ao optar pela segregação de D. Quixote ao final de sua obra. É a guinada ao novo modelo que passaria a viger pouco a pouco e, após, se consolidaria, para apenas no final do século XX passar a ser questionado e revisto.

Cervantes manteve D. Quixote junto a seus amigos e parentes, e no segundo volume da obra, publicada um ano após o apócrifo de Avellaneda, repete a fórmula utilizada no primeiro volume, optando pela morte do manchego ao final do romance, até, supondo-se, como forma de evitar que novas investidas apócrifas viessem a macular o seu louco herói.

Choza é bastante ilustrativo ao dizer que a razão de acolhimento da loucura em Cervantes é o sentido de reconhecimento que se processa na obra. O louco não é visto como o diferente, a ser isolado, mas como o amigo, o vizinho, o parente, o semelhante:

¿Por qué es posible querer a unos personajes así?, ¿por qué es posible querer a una persona así? Porque está loca, 
porque es una ruina humana, porque está desperdigada em trozos que merecen ser recogidos, mucho más de lo que merecen los muertos ser enterrados porque esos trozos pertenecen a una vida que aún está siendo vivida, porque esas vidas tan simples, tan deterioradas, valen la pena, y valen la pena porque son la vida de un amigo, de un vecino, de un pariente, de un semejante, de alguién mío, porque esa persona tambíén soy yo, porque yo me veo y me reconozco en ella (2005, p. 75).

O contraponto entre as visões de Cervantes e Avellaneda sobre a loucura indica que, mesmo contemporâneas, ambas as obras apresentam visões bastante diversas a respeito do tema, sendo notável o fato de Cervantes ter se antecipado ao modelo que hoje vigora no tocante à atenção à saúde mental, privilegiando o envolvimento da família e da comunidade, enquanto Avellaneda caminha no sentido da segregação de D. Quixote.

\section{AS CONTRADIÇÕES DO ORDENAMENTO JURÍDICO BRASILEIRO}

Transpondo esse contraponto para o ordenamento jurídico brasileiro, percebe-se, também aqui, posições diversas e mesmo contraditórias na legislação a respeito do trato com a loucura.

Enquanto a Lei Federal n. 10.216/2001 estabelece a internação como exceção, prevendo a regra do tratamento comunitário e do envolvimento da família, aos moldes da opção cervantina e de acordo com o novo modelo vigente, centrado na cidadania da pessoa com sofrimento psíquico, o Código Civil de 2002, ao dispor sobre os interditos, estabelece, em seu artigo 1.767, que aqueles que, por enfermidade ou deficiência mental, não tiverem o necessário discernimento para os atos da vida civil, os "deficientes mentais", os "ébrios habituais", os viciados em tóxicos e os "excepcionais sem completo desenvolvimento mental” serão recolhidos em estabelecimentos adequados, quando não se adaptarem ao convívio doméstico.

A existência do dispositivo civilista, na evidente contramão da evolução social e legal no trato da matéria, somente se explica pela visão ainda imperante no inconsciente coletivo da sociedade no sentido de que "lugar de louco é no hospício". Ou seja, no limiar do século XXI o modelo superado continua a influenciar o modo de pensar das pessoas e o próprio processo legislativo. 
Não se rompe um processo complexo e crescente no sentido da segregação do diferente, processo que levou quatrocentos anos e que somente em meados do século passado começou a ser questionado e revisto, de forma imediata e sem riscos de retrocesso.

A contradição legal exposta é apenas um demonstrativo da fase delicada em que nos encontramos. Todo um novo modelo está sendo construído, mas as ruínas do antigo ainda estão bastante visíveis, a ponto de em alguns momentos se sobreporem ao novo.

O processo de migração é lento e doloroso. Não se trata de apenas mudar as estruturas, mas também as mentalidades. E isso parece ser o mais difícil. Escreve Sergio Alarcon, referindo Foucault:

Uma nova maneira de pensar que inclua a loucura em um sentido mais alargado, com alguma positividade - talvez até como uma experiência de libertação -, pressupõe necessariamente uma nova interpretação de nós mesmos, de como nos pensamos, das práticas que isso implica, suas relações, e, dessa maneira, deve levar em conta especialmente a questão do sujeito, suas vertentes, seus antagonismos, na medida em que é a invenção do sujeito que funda as práticas nas quais nos tornamos objetos de nosso próprio conhecimento (2000, p. 25).

É o próprio Dom Quixote quem sentencia:

- A liberdade, Sancho, é um dos mais preciosos dons que os céus deram aos homens; com ela não se podem igualar os tesouros que encerra a terra nem o mar encobre; pela liberdade, assim como pela honra, se pode e deve aventurar a vida, e, pelo contrário, o cativeiro é o maior mal que pode vir aos homens (Cervantes, 2010b, p. 601).

O fato é que hoje estamos vivenciando a construção de um novo modelo de atenção à saúde mental, fulcrado na cidadania e na liberdade do sujeito, mas a proximidade temporal da escalada segregacionista do louco que se deu nos últimos quatrocentos anos, cuja cessação apenas começou a ocorrer em meados e final do século passado, ainda nos traz situações contraditórias, como a do mencionado dispositivo civilista, e dificuldades na implantação do novo paradigma.

\section{CONCLUSÃO}

As andanças do Cavaleiro da Triste Figura, reunidas na obra cervantina, patrimônio da humanidade, têm inspirado variadas 
interpretações ao longo de sua história, algumas enfatizando sua loucura tragicômica, outras, o idealismo que motiva suas ações.

A loucura, contudo, acompanha a obra em todos os momentos. É a loucura de Dom Quixote e a liberdade dada a ela por Cervantes que possibilitam as aventuras do manchego e a construção da obra em si, não sendo exagerado dizer que sem a equação resultante da loucura e da liberdade do protagonista não haveria Dom Quixote.

Cervantes concebe seu Cavaleiro como um ser humano livre no mundo, mas respeitado em sua singularidade. Há muitos momentos de dificuldade e risco relacionados à condição do fidalgo manchego, mas é a narrativa desses momentos, com Dom Quixote afirmando sua verdade e imbuído de valores humanitários de justiça, fidelidade e solidariedade, que ditam a tônica da abordagem cervantina. Uma tônica marcada pela opção de manter Dom Quixote na sociedade, onde faz amigos e inimigos, e junto a seus conhecidos e familiares.

O fantasma da segregação e da nulificação do fidalgo é representado pela opção de Avellaneda, que ao final de sua obra apócrifa encerra o manchego na casa de loucos de Toledo, prenunciando a brutal segregação que se estenderia dali aos próximos quatrocentos anos, condenando a loucura ao silêncio.

$\mathrm{O}$ ordenamento jurídico ora vigente, resultado das reformas psiquiátricas que passaram a se desenvolver após o fim da Segunda Guerra Mundial, e no Brasil tendo como marco legal a Lei Federal n. 10.216/2001, prima pelo respeito à cidadania e à liberdade do indivíduo, estabelecendo uma política de inserção da pessoa com transtornos mentais na sociedade, com a participação da família e dos serviços comunitários de saúde mental como prioritários no tratamento, afigurando-se a segregação como absoluta exceção à regra vigente.

Todavia, o fantasma de Avellaneda persiste, representado pelo senso comum marcado pela ainda recente e duradoura história do isolamento imposto aos loucos, ao ponto de haver espaço para o retrógrado artigo 1.767 do Código Civil brasileiro, a ameaçar com segregação aquele que "não se adaptar ao convívio doméstico", encorajando o impulso segregacionista como perene alternativa a dificuldades encontradas.

Que prevaleça Cervantes! 


\section{REFERÊNCIAS}

ALARCON, Sergio. Aos homens de boa vontade: estudos sobre sujeição e singularidade. In: AMARANTE, Paulo (ed.). Ensaios: subjetividade, saúde mental, sociedade. Rio de Janeiro: Editora Fiocruz, 2000, p. 25-40.

ALENCAR, Paulo Sérgio Silva de et al. Textos de apoio em saúde mental. Rio de Janeiro: Fiocruz, 2003.

BRASIL. Lei n. 10.216, de 6 de abril de 2001. Disponível em: <http://www.planalto.gov.br/ccivil_03/Leis/LEIS_2001/L10216.htm>. Acesso em: 5 mar. 2012.

BRASIL. Lei n. 10.406, de 10 de janeiro de 2002. Institui o Código Civil. Disponível em: <http://www.planalto.gov.br/ccivil_03/Leis/2002/L10 406.htm>. Acesso em: 5 mar. 2012.

CERVANTES, Miguel de. O engenhoso fidalgo D. Quixote de La Mancha, primeiro livro. Tradução e notas de Sérgio Molina. São Paulo: Editora 34, 2010a.

CERVANTES, Miguel de. O engenhoso cavaleiro D. Quixote de La Mancha, segundo livro. Tradução e notas de Sérgio Molina. São Paulo: Editora 34, 2010b.

CHOZA, Jacinto. Don Quijote y la dignidad del loco. In: Instituto de Mayores y Servicios Sociales (IMSERSO). La salud mental es cosa de todos: primer congreso: el reto de la atención comunitaria de la persona con trastorno mental grave desde los servicios sociales. Madri: Artegraf, 2005, p. 69-75. Disponível em: <http://books.google.es/books?hl $=$ es\&lr $=\& \mathrm{id}=\mathrm{F} 3 \mathrm{hVs} 5 \mathrm{gUzkUC \& oi}=\mathrm{fnd} \& \mathrm{pg}=\mathrm{PA} 69 \& \mathrm{dq}=$ Quijote + Derecho\&ots $=$ VNoTmfVdcf\&sig=6oFjr6iaXEDBpPQCu9G6q5wS-Xc\&redir_esc $=\mathrm{y} \# \mathrm{v}=$ onepage\&q=Quijote\%20Derecho\&f=true $>$. Acesso em: 19 mar. 2012.

CRUZ, Ana Aparecida Teixeira da. Dimensões da loucura nas obras de Miguel de Cervantes e Lima Barreto: Don Quijote de La Mancha e Triste Fim de Policarpo Quaresnma. Dissertação (Mestrado em Letras) Universidade de São Paulo, São Paulo, 2009. 205 f.

FERNÁNDEZ DE AVELLANEDA, Alonso. El Ingenioso hidalgo Don Quijote de La Mancha: que contiene su tercera salida y es la quinta parte de sua aventuras. Madri: Editorial Castalia, 1999.

FOUCAULT, Michel. História da loucura: na idade clássica. 9. ed. Trad. de José Teixeira Coelho Neto. São Paulo: Perspectiva, 2010.

FOUCAULT, Michel. Microfísica do poder. Trad. de Roberto Machado. Rio de Janeiro: Edições Graal, 2011.

GARCÍA SALINERO, Fernando. Introducción crítica sobre la obra y su autor. In: FERNÁNDEZ DE AVELLANEDA, Alonso. El Ingenioso hidalgo Don Quijote de La Mancha: que contiene su tercera salida y es la quinta parte de sus aventuras. Madri: Editorial Castalia, 1999, p. 7-37.

VASCONCELLOS, Jorge. Filosofia e loucura: a ideia de desregramento e a filosofia. In: AMARANTE, Paulo (ed.). Ensaios: subjetividade, saúde mental, sociedade. Rio de Janeiro: Editora Fiocruz, 2000, p. 13-23. 
VIEIRA, Maria Augusta da Costa. Apresentação da segunda parte de D. Quixote. In: CERVANTES, Miguel de. O engenhoso cavaleiro D. Quixote de La Mancha, segundo livro. Tradução e notas de Sérgio Molina. São Paulo: Ed. 34, 2010, p. 13-31.

Submetido: 29/12/14

Aceito: 21/04/15 